\title{
THE DEPOSITION PROCESS OPTIMIZATION BY CONTROLLING OF THE PIEZO ELEMENTS IN THE PRINT HEAD
}

\author{
Peter LUKÁCS ${ }^{*}$, Alena PIETRIKOVÁ*, Jerzy POTENCKI**, Grzegorz TOMASZEWSKI** \\ *Department of Technologies in Electronics, Faculty of Electrical Engineering and Informatics, \\ Technical University of Košice, Letná 9, 04200 Košice, Slovak Republic, Tel.: +421 55602 3013, E-mail: peter.lukacs@tuke.sk \\ ${ }^{* *}$ Department of Electronic and Communications Systems, Rzeszow University of Technology, \\ al. Powstancow Warszawy 12, 35-959 Rzeszow, Poland
}

\begin{abstract}
The aim of this paper is optimization of the deposition process in jetlab ${ }^{\circledR} 4 x l-A$ inkjet printer by controlling of the actuating signal drives the piezo element in print head used in the Department of Technologies in Electronics at Technical University of Kosice. The implemented optimization process significantly contributes to the precision printing of the silver based nano-inks onto the polymeric flexible and rigid substrates. By changing the shape of the actuating signal the small volumes of drops are achieved which allows to create the structures with smaller width and higher precision. The careful adjustment of the inkjet printer before the printing is a time consuming process which had to be done for every kind of nano-inks as well as for substrates. This paper offers the optimized actuating signal for silver based nano-ink UTDAgIJ manufactured by UT Dots, Inc., using the nozzle with diameter $70 \mu \mathrm{m}$.
\end{abstract}

Keywords: InkJet printing, optimization process, print head, nano-ink

\section{INTRODUCTION}

Nowadays the possibility of the creation of precise structures with high accuracy is most desirable mainly in the case of technologies in electronics. Introduction of the nano-technology to the field of electronics brings the completely new opportunities to creation the special applications, where small dimensions, thin layers, flexibility and precision play a key role $[1,5]$.

The unstoppable development of nanotechnology brings new possibilities in the area of electronics technology. One of these technologies is inkjet printing technology (IJP), which offers a lot of advantages, such as creation conductive, semi conductive, isolation or other function layers onto various flexible or rigid substrates. Described non-contact printing method presents the digital printing, which works with small ink quantities with very low viscosity based on nanoparticles of special materials. This printing nano-technology is suitable especially for applications, where the precise printing with high accuracy is desirable [1].

The deposition process of nano-ink onto the flexible substrates with high precision, creation the suitable adhesion mechanism and recommended curing conditions are influenced by many technological steps, which are closely related. Uncontrolled process of the ink spreading on the surfaces causes the formation of the coffee ring effect, as well as the inhomogeneous structure. The compatibility of the concrete nano-ink, polymeric substrate, nozzle diameter as well as the inkjet printer requires the special approach for finding the best technological aspects for creation the final structures with high quality. The optimization process of the drops' deposition is major challenge in this nanotechnology solved worldwide $[1,5,6,7]$.

\section{INKJET PRINTING TECHNOLOGY (IJP)}

The IJP presents the deposition technique of small volumes of nanoink onto the flexible polymeric substrates using the piezoelectric phenomena. The described deposition technique allows the applying of very thin layers (approx. 1 um) of conductive, semi conductive, isolation and special materials in the form of nanoparticles onto the polymeric substrates. Described non-contact printing method presents the digital printing, which works with small ink quantities with very low viscosity based on nanoparticles of special materials. This printing technology is suitable especially for applications, where the precise printing with high accuracy is desirable $[1,8]$.

The described technology offers the very wide range of usable materials. There are various types of polymer flexible substrates that could be used for flexible electronic devices, e.g. polyethylene terephthalate (PET), polyimide (PI) and polyethylene naphthalene (PEN) $[1,2]$.

Inks, used for inkjet printing technology may be divided into 3 groups. The first, most used inks are based on nanoparticles of conductive organic or metal (silver, gold, copper) materials. The second group consists of semi conductive inks, which are based on carbon nanotubes, as well as on organic materials, such as PQT12 or P3HT. The last group of inks serves to creating of isolation layers. For this purpose, organic (PVP, PMMA) and inorganic $\left(\mathrm{Zr}, \mathrm{TiO}_{2}, \mathrm{SiO}_{2}\right)$ materials are used [3, 4].

The deposition process of nano-ink onto the flexible substrates with high precision, creation the suitable adhesion mechanism and recommended curing conditions are influenced on many technological steps which are closely related. These technological aspects represent the most important technological parameters, which must be taken into consideration during the deposition settings [1].

\section{DROPS GENERATION}

For optimizing of the drops generation from nozzle, there is the necessity of understanding the basic principle of drop formation. To simplify the theoretical modeling process, several assumptions have been made [9]:

1) the fluid is Newtonian and incompressible,

2) the diffusion between the ambient environment and the fluid is negligible, 
3) the effects of the gravity are negligible.

With these characteristics, the continuity equation and Navier-Stokes equations governing the liquid motion are given in cylindrical, axisymmetric coordinates $(\mathrm{r}, \mathrm{z})$ as [9]

$\frac{\partial u}{\partial z}+\frac{1}{r} \frac{\partial(r v)}{\partial r}=0$

$\rho\left(\frac{\partial v}{\partial t}+v \frac{\partial v}{\partial r}+u \frac{\partial v}{\partial z}\right)=\mu\left[\frac{\partial}{\partial r}\left(\frac{1}{r} \frac{\partial(r v)}{\partial r}\right)+\frac{\partial^{2} v}{\partial z^{2}}\right]$

$+\frac{\partial F_{b}}{\partial r}-\frac{\partial P}{\partial r}$

$\rho\left(\frac{\partial u}{\partial t}+v \frac{\partial u}{\partial r}+u \frac{\partial u}{\partial z}\right)=\mu\left[\frac{1}{r} \frac{\partial}{\partial r}\left(r \frac{\partial u}{\partial r}\right)+\frac{\partial^{2} u}{\partial z^{2}}\right]$

$+\frac{\partial F_{b}}{\partial z}-\frac{\partial P}{\partial z}$

Where $u$ and $v$ are the axial and radial components of the velocity field, respectively, $P$ is the fluid pressure, $\mu$ is the fluid viscosity and $F_{b}$ is the volume force dominated mainly by surface tension [9].

The volume force $F_{b}$ can be translated as a continuous effect of surface tension an interface and be given by next equation [9]:

$F_{b}=f_{\sigma} \delta_{\sigma}$

Where $f_{\sigma}$ is the surface tension force per unit interfacial area and $\delta_{\sigma}$ is a surface delta function restricting the surface tension force $F_{b}$ being applied in the minute bounded region containing the interface. The fluid flow rate $Q$ can be defined as [9]:

$\frac{\partial Q}{\partial r}=u r$ and $\frac{\partial Q}{\partial z}=-v r$

The steam function can be written as:

$\frac{\partial^{2} Q}{\partial z^{2}}+r \frac{\partial}{\partial r}\left(\frac{1}{r} \frac{\partial Q}{\partial r}\right)=r\left(\frac{\partial u}{\partial r}-\frac{\partial v}{\partial z}\right)$

The jet configuration and reference frame of droplet formation from the inkjet nozzle is illustrated in the Fig. 1. As the liquid is being ejected out of the nozzle, a normal stress or pressure jump is generated at the surface relative to ambient gas pressure. The required surface pressure conditions in the local frames can be given as [9]:

$\frac{P}{\rho}-\left(\frac{P}{\rho}\right)_{\text {air }}=\frac{\sigma}{\rho}\left(\frac{\cos \alpha}{r}-\frac{\partial \alpha}{\partial \tau}\right)+\frac{2 \mu}{\rho}\left(\frac{\partial u_{\eta}}{\partial \eta}+u_{\tau} \frac{\partial \alpha}{\partial \eta}\right)$

where

$u_{\eta}=-\frac{1}{r} \frac{\partial Q}{\partial \tau}$ and $u_{\tau}=-\frac{1}{r} \frac{\partial Q}{\partial \eta}$

are the normal and tangential ejection velocities with respect to the local surface coordinates, respectively, $P$ and $\rho$ are the internal pressure and density of the liquid, respectively and $\sigma$ is the surface tension coefficient.

The pressure jump at $P_{j u m p}$ at the local liquid-air interface can be calculated as [9]:

$$
\begin{aligned}
& P_{\text {jump }}=P-P_{\text {air }}=\left(\frac{\rho}{\rho_{\text {air }}}-1\right) P_{\text {air }}+\sigma\left(\frac{\cos \alpha}{r}-\frac{\partial \alpha}{\partial \tau}\right) \\
& +2 \mu\left(\frac{\partial u_{\eta}}{\partial \eta}+u_{\tau} \frac{\partial \alpha}{\partial \eta}\right)
\end{aligned}
$$

If the value of $P_{\text {jump }}$ at local parts of the liquid-air interface overcomes the constraint of volume force $F_{b}$ a certain volume of liquid will break off from the liquid surface, emerge into the air phase and generate companion drops.

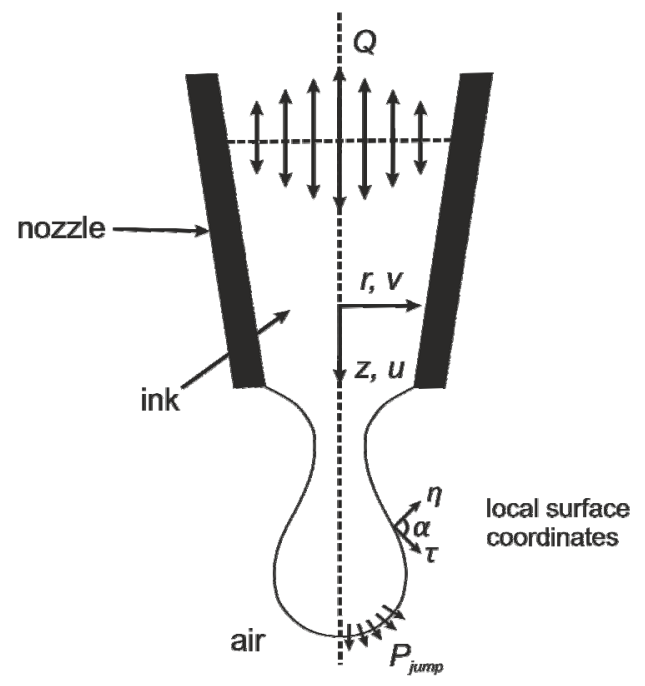

Fig. 1 Schematic of jet configuration and reference frame

The dispensers manufactured by MicroFab, used in the MicroFab jetlab ${ }^{\circledR}$ 4xl-A inkjet printer, are actuated piezoelectrically. An annular piezoelectric (PZT) element, poled radially, is bonded to a glass tube with an integrated nozzle and orifice. The glass tube is mounted in a protective housing and, at the supply end, bonded to a fitting, illustrated in the Fig. 2 [10].

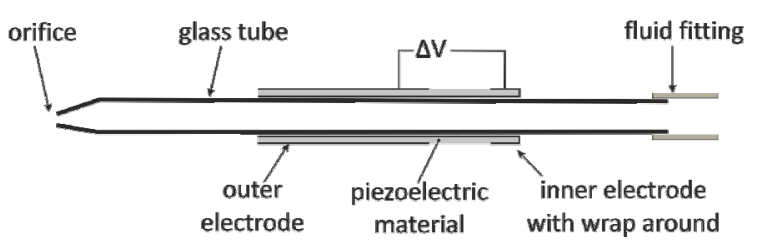

Fig. 2 Schematic of MicroFab's glass dispenser

When applying a voltage differential, the electrical field is generated between the inner and outer electrodes causing the piezoelectric actuator to expand radially (and contract axially) or, depending on the voltage polarity and poling, contract radially (and expand axially). The deformation occurs only along the portion where both electrodes are present, as the electric field is not generated in the region without electrodes and the wrap around region of the inner electrode [10].

The simplest actuation signal consists of a trapezoidal waveform that is applied, whenever a drop is desired, to one electrode while the other electrode is electrically grounded, shown in the Fig. 3. Deformation occurs during the transition periods (rise and fall) and ceases during the constant voltage (dwell) period [10]. 


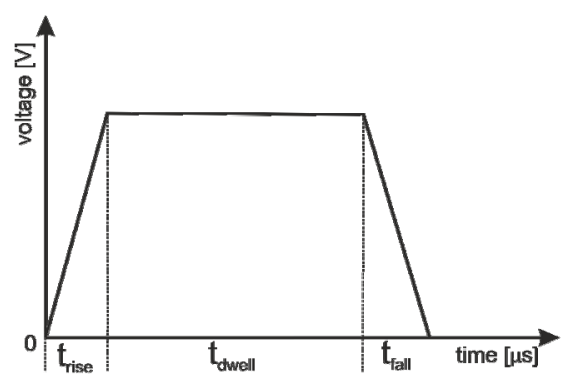

Fig. 3 Simplest actuating voltage to generate a drop

During the rise time, the tubular PZT expands its circumference while becoming thinner and shorter. This fast deformation is transmitted through the epoxy bond to the glass tube and results in an outwards motion of the inner glass surface which produces a negative pressure (with respect to the equilibrium). The negative pressure travels in the fluid at the speed of sound along the glass tube in the form of an expansion acoustic wave to both the orifice and the supply end. The expansion wave is reflected as a compression wave (higher pressure than the equilibrium pressure in the glass tube) at the supply end and travels back towards the orifice. If the dwell time is selected to start when the positive pressure wave matches the piezoelectric actuator, the inwards motion of the inner glass surface reinforces it resulting in a faster and larger droplet [10].

More complex signals can include a negative pulse (or "echo") as shown in the Fig. 4. This signal is referred to as "bipolar". In general, $\mathrm{V}_{0}=0$, but a nonzero baseline voltage can be employed as well. It is possible to have $V_{2}=-V_{1}$ or different [10].

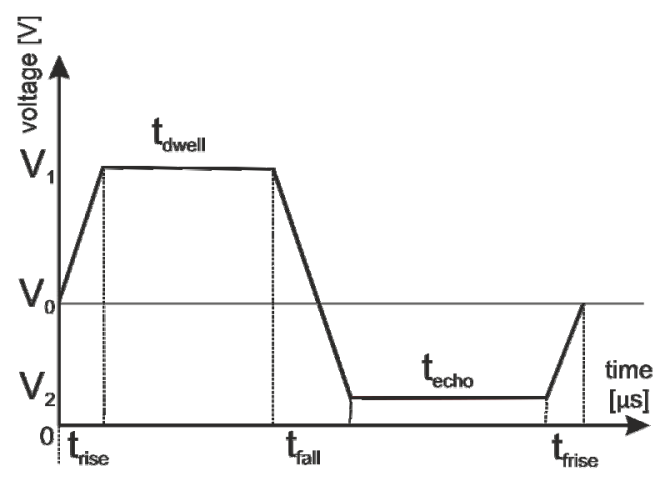

Fig. 4 Bipolar actuating signal

The timing is determined by the length of the glass tube and the speed of sound in the dispensed solution. Based on the scales involved, the "dwell" and "echo" are in the tens (up to hundreds) of microseconds. The transition times "rise", "fall" and "final rise" are several microseconds long. For some fluids, the control the duration of the transition periods could increase the stability of drop generation [10].

\section{OPTIMIZATION PROCESS}

For the reason of achieving the small volume of generated drops, selected values of the actuating signal were modified as it is shown in the Fig. 5. Typical values which have the significant impact on the drops' parameters were optimized, such as dwell time and dwell voltage, as well as echo time and echo voltage. Realized experiments show that the remaining values of the actuating signal have the negligible impact on the final shape and behavior of the generated drop. The shape and volume of the generated nano-ink drop has the significant impact on the final quality of the deposited structure. The thickness of the layer, smooth edges as well as the homogeneity of the structures play a key role for maintaining the electrical and mechanical properties of the nano-ink structures indicated in the data lists. For this reason, the optimizing

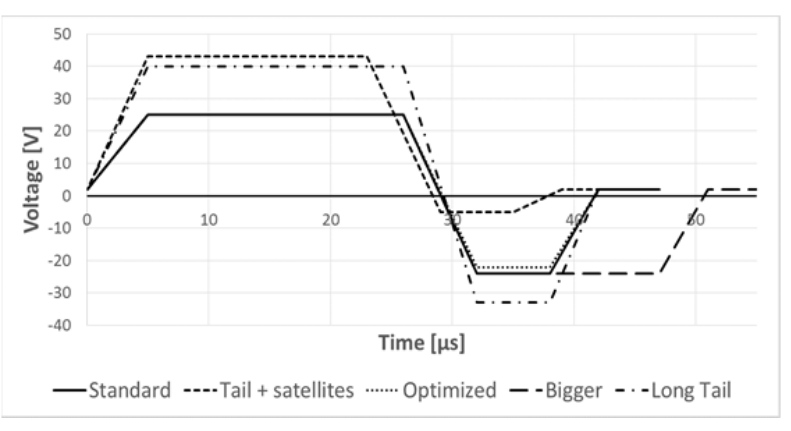

Fig. 5 Modified actuating signals

In the Fig. 6 is illustrated the optimal shape of the generated drop but the volume of the drop is too large. Drops with large volumes occur the excessive ink spreading after the impact on the substrate's surface which not allows to create the structures with high precision and accuracy. This is the result of too long echo time with comparison of the dwell time.

In the Fig. 7 is shown the drop ejection sequence, where during the drop generation the tail after the main drop is created. This phenomenon is the undesirable effect and has the significant negative impact on the quality of the final structure. In general the tail during the flight connects to the major drop, deviates from the straight track or extinguishes. The tail occurs the larger ink volume on substrates' surfaces after the impact. This phenomenon is the result of the excessively high values of the dwell voltage and vice versa for the echo voltage.

In the Fig. 8 is shown the next undesirable effect in the drop generation. In this case the tail is separated from the major drop and creates the detached drop - satellite drop. The satellite drop can be connected with the major drop during the flight, deviated from the straight track or can outrun the major drop. Satellite drops are occurred if the ratio between dwell voltage and echo voltage is not maintained adequately.

Drops presented in the Fig. 7 and Fig. 8 are not suitable for the applications where the small dimensions and thin layer play a key role. In the Fig. 9 is presented the standard drop ejection sequence suitable for any nano-ink. This actuating signal has the optimal values for controlling the piezo-element and generating the drops with strictly defined shapes and other parameters such as the drop volume and velocity of the drop. On the other hand, there is the necessity for achieving the smaller volume of the drops for the precise printing. 


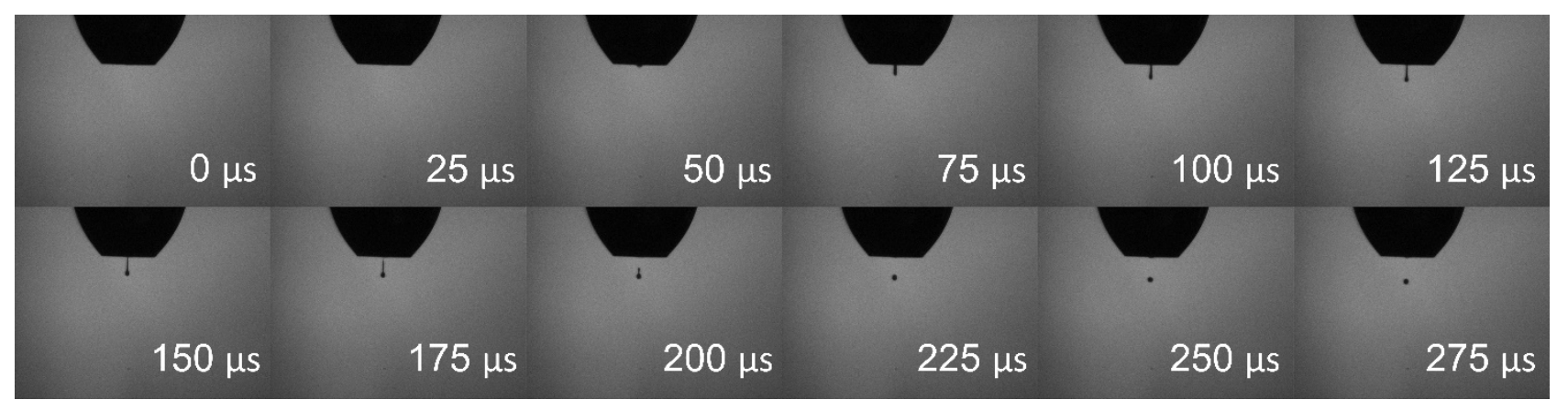

Fig. 6 Drop ejection sequence - Large volume of drops

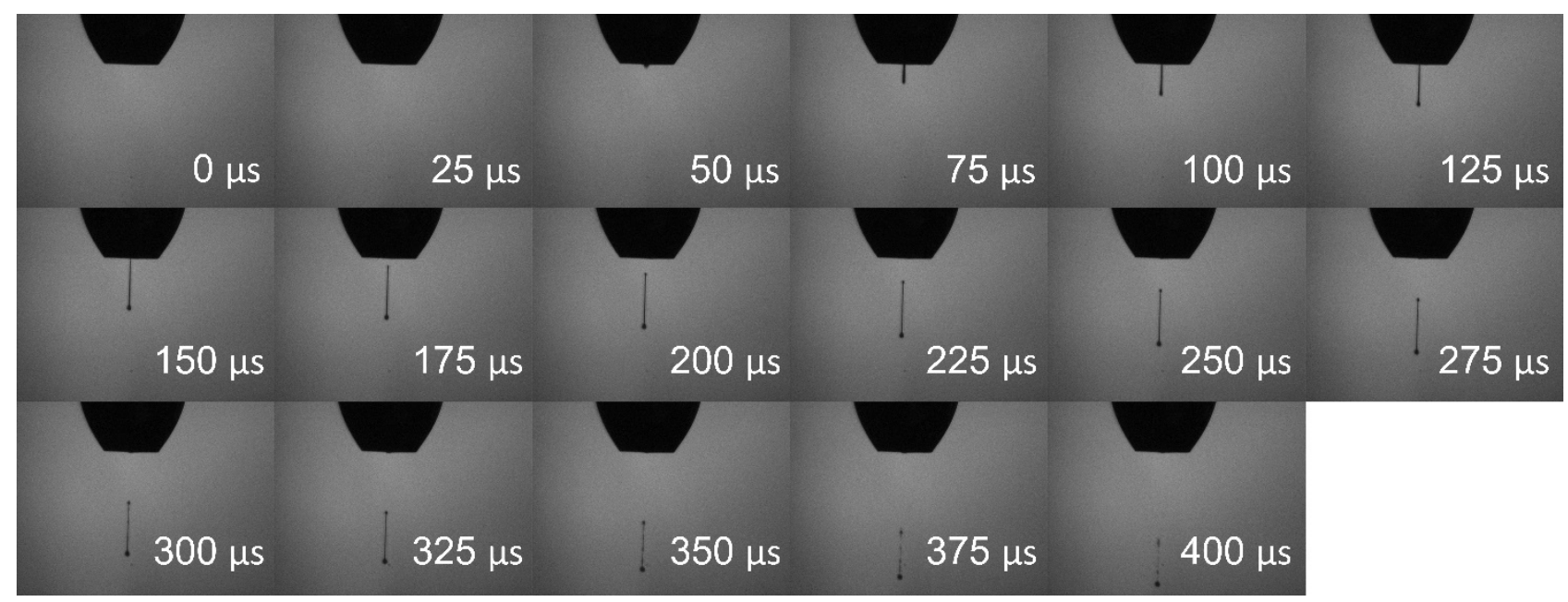

Fig. 7 Drop ejection sequence - Long Tail

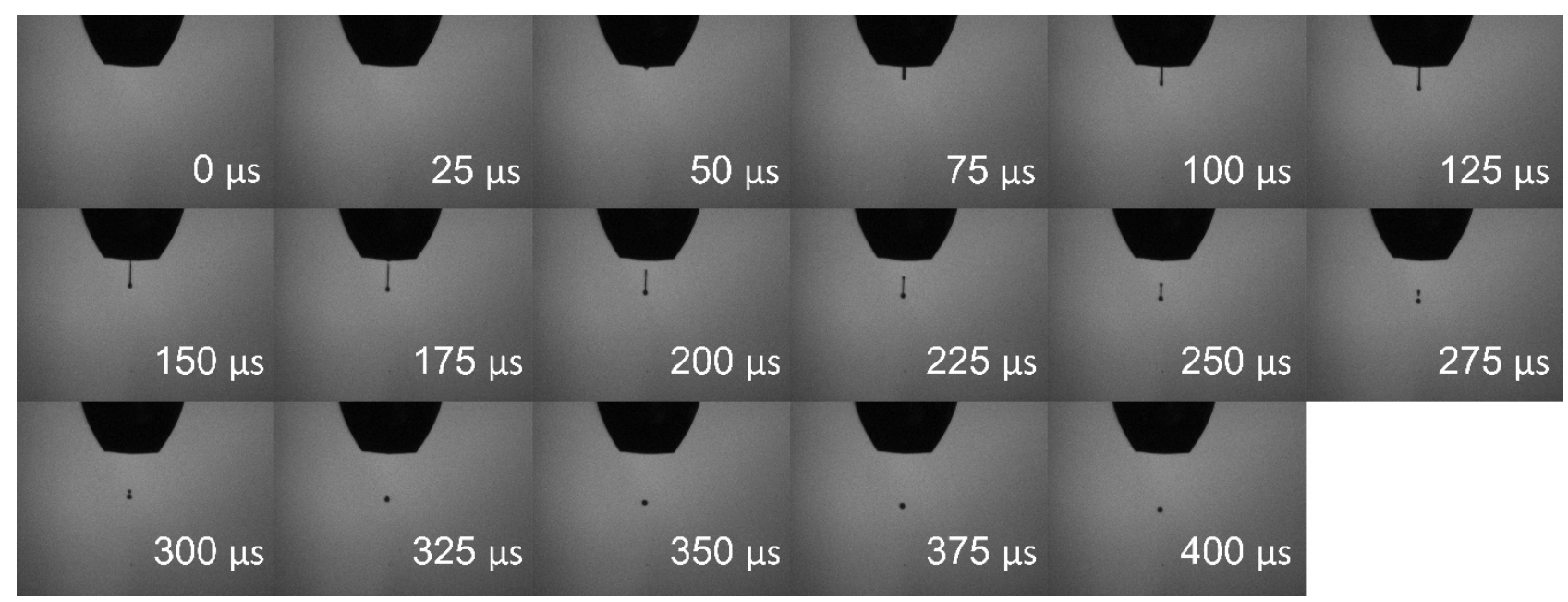

Fig. 8 Drop ejection sequence - Long tail and satellite drop 


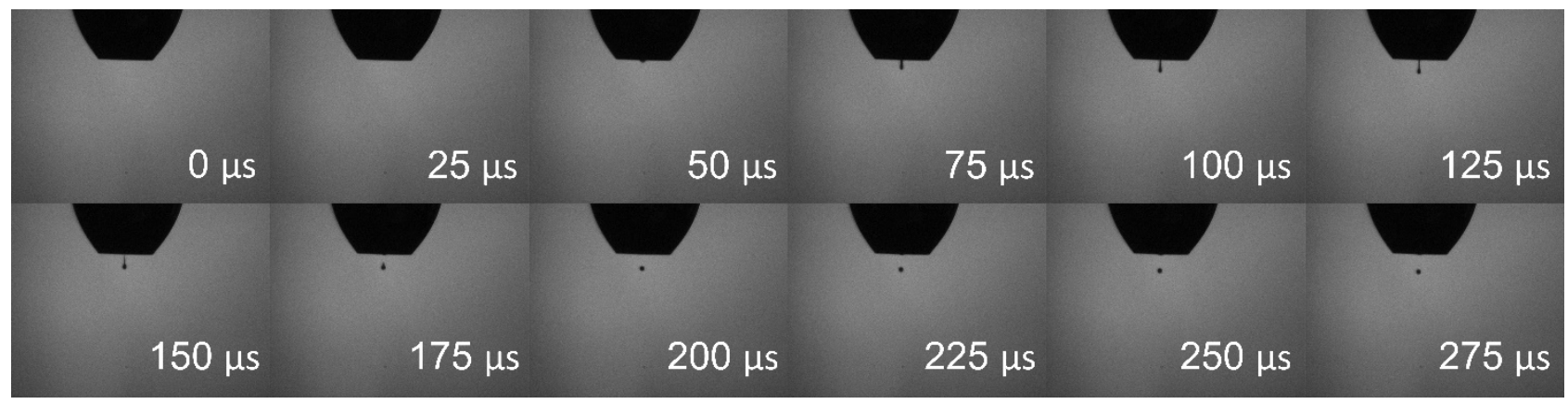

Fig. 9 Drop ejection sequence - Standard actuating signal

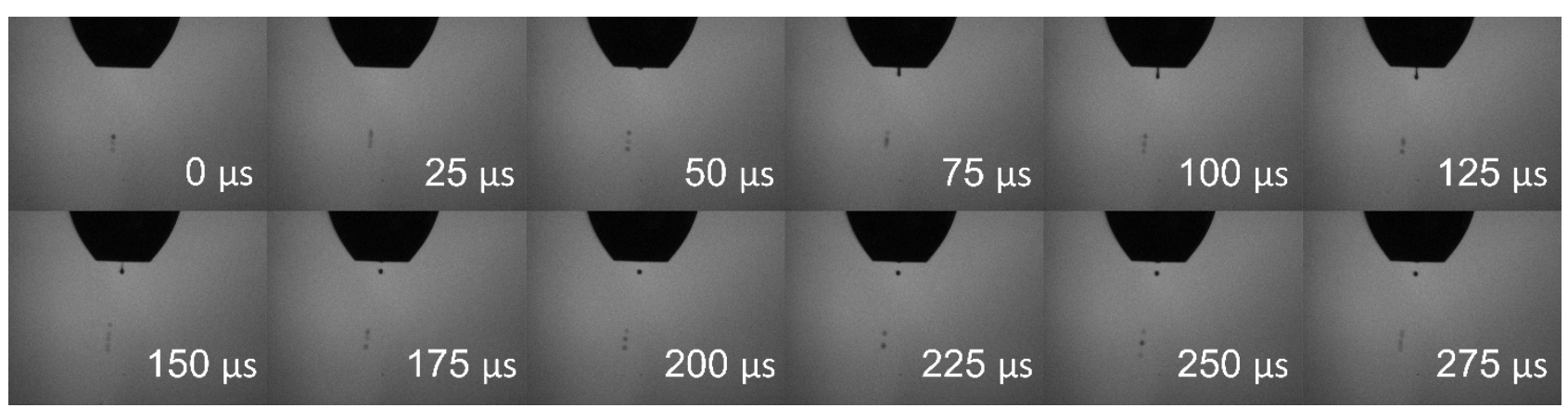

Fig. 10 Drop ejection sequence - Optimized actuating signal

For the reason mentioned above, the standard actuating signal illustrated in the Fig. 9 has been further optimized. By increasing the echo voltage, the volume reduction of the drop has been achieved, which is shown in the Fig. 10. It is very important to take into the consideration that the achieved small drop volume presents the minimum wherein the nozzle is not dried caused by the weak flow of the ink during the nozzle.

\section{CONCLUSION}

This paper describes the deposition process optimization by managing of the actuating signal which controls the piezo elements in the print head. The results achieved by optimization of the actuating signal are illustrated by drop ejection sequences and represent an important contribution to the miniaturization process of electronics on the flexible substrates.

\section{ACKNOWLEDGMENTS}
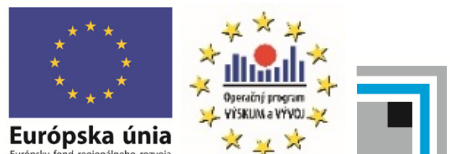

Európska únia

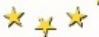

Paper is the result of the Project implementation: University Science Park TECHNICOM for Innovation Applications Supported by Knowledge Technology, ITMS: 26220220182, supported by the Research \& Development Operational Programme funded by the ERDF."We support research activities in Slovakia/This project is being co-financed by the European Union.
This work was supported by the Slovak Research and Development Agency under the contract No. APVV-140085: Development of New Generation Joints of Power Electronics Using Nonstandard Sn-Based Alloys.

This paper was supported by the grant FEI-2015-11.

This paper was developed with support of the Project "Centrum excelentnosti integrovaného výskumu a využitia progresívnych materiálov a technológií v oblasti automobilovej elektroniky" (Centre of Excellence of Integrated Research and Exploitation the Advanced materials and Technologies in the Automotive Electronics), ITMS 26220120055, that is co-financed from Structural Funds EU ERDF within Operational Program Research and Development OPVaV2009/2.1/03-SORO and preferred axis 2 Support of Research and Development.

\section{REFERENCES}

[1] PIETRIKOVA, A. - LUKACS, P. - JAKUBECZYOVA, D. et al.: Surface analysis of polymeric substrates used for inkjet printing technology, Circuit World, Vol. 42, No. 1, pp. 9-16, 2016.

[2] TOMASZEWSKI, G. - POTENCKI, J. WAŁACH, T. - PILECKI, M.: Investigation of ink spreding on various substrates in inkjet technology, $38^{\text {th }}$ International Conference of IMAPS-CPMT, Rzeszów-Czarna, 2014.

[3] DANIEL, J.: Printed Electronics: Technologies, Challenges and Applications, International Workshop of Flexible \& Printed Electronics, Korea, 2010 . 
[4] FELBA, J. - SCHAEFER, H.: Materials and technology for conductive microstructures W: Nanopackaging: nanotechnologies and electronics packaging, Ed. James E. Morris, New York, NY: Springer, 2008, pp. 239-263.

[5] LI, J. - LEMME, M. C. - ÖSTLING, M.: Inkjet Printing of 2D Layered Materials, ChemPhysChem, Vol. 15, No. 16, pp. 3427-3434, 2014.

[6] PARK, S. J. - LEE, E. J. - KWON, S. H.: Influence of Surface Treatment of Polyimide Film on Adhesion Enhancement between Polyimide and Metal Films, Bulletin of the Korean Chemical Society, Vol. 28, No. 2, pp. 188-192, 2007.

[7] LI, S. - LIU, P. - WANG, Q.: Study on the effect of surface modifier on self-aggregation behavior of Ag nano-particle, Applied Surface Sciences, Vol. 263, No. 1, pp. 613-618, 2012.

[8] SHIMONI, A. - AZOUBEL, S. - MAGDASSI, S.: Inkjet printing of flexible high-performance carbon nanotube transparent conductive films by "coffee ring effect", Nanoscale, Vol. 6, No. 19, pp. 1090511490, 2014.

[9] ZHANG, H. - WANG, J. - LU, G.: Numerical investigation of the influence of companion drops on drop-on-demand ink jetting, Journal of Zhejiang University-SCIENCE A, Vol. 13, No. 8, pp. 584$595,2012$.

[10] MicroFab Technologies Inc.: Ink-Jet Microdispensing Basic Set-up, 2012.

Received June 15, 2016, accepted September 20, 2016

\section{BIOGRAPHIES}

Peter Lukács was born on 1989. In 2013 he graduated (MSc) with distinction at the Department of Technologies in Electronics of the Faculty of Electrical Engineering and
Informatics at Technical University of Košice. Now, he is a $\mathrm{PhD}$. student at the same department. His scientific research is oriented to the inkjet printing technology focusing on the material oriented research and applying the nanoparticles onto to polymeric substrates.

Alena Pietriková obtained M.Sc. in material science in 1980 and Ph.D. in 1986 at Technical University of Košice, Slovakia. Currently she is professor of electro-technology and materials at the Department of Technologies in Electronics of the Faculty of Electrical Engineering and Informatics at Technical University of Košice. She is coauthor of more than 230 scientific publications, 5 patents and 5 books. The most of her research works is focused on study of materials and technologies in electronics.

Jerzy Potencki was born in 1953. He received his MSc degree in electrical engineering from the Rzeszów University of Technology (RzUT) in 1978, PhD in microelectronics from the Wrocław University of Technology in 1986. Since 1995 he has been employed as professor in the Department of Electronic and Communication Systems of RzUT and as a Head of Department from 2013. His scientific interest was focused generally on microelectronics technologies, especially multilayer, thick-film sensors as well as on issues of the heat transfer and temperature field distribution in hybrid microelectronic circuits.

Grzegorz Tomaszewski was born in 1985. He received his BSc. and MSc. diploma in Electronics and Telecommunications from the Rzeszów University of Technology in 2009 and 2011, respectively. Since 2013 he participates in research project "Synthesis of autonomous semi-passive transponder dedicated to operation in anticollision dynamic RFID systems". His scientific research is focused on inkjet printing technology and planar flexible antennas for energy harvesting systems. Currently he has worked in the Department of Electronic and Communications Systems in Rzeszów University of Technology. 